\title{
Comparison between Silicon-Carbide and diamond for fast neutron detection at room temperature
}

\author{
O.Obraztsova, L.Ottaviani, A.Klix, T. Döring, O. Palais, A. Lyoussi
}

\begin{abstract}
Neutron radiation detector for nuclear reactor applications plays an important role in getting information about the actual neutron yield and reactor environment. Such detector must be able to operate at high temperature (up to $600^{\circ} \mathrm{C}$ ) and high neutron flux levels. It is worth nothing that a detector for industrial environment applications must have fast and stable response over considerable long period of use as well as high energy resolution. Silicon Carbide is one of the most attractive materials for neutron detection. Thanks to its outstanding properties, such as high displacement threshold energy (20-35 eV), wide band gap energy $(3.27 \mathrm{eV})$ and high thermal conductivity $(4.9 \mathrm{~W} / \mathrm{cm} / \mathrm{K})$, $\mathrm{SiC}$ can operate in harsh environment (high temperature, high pressure and high radiation level) without additional cooling system. Our previous analyses reveal that $\mathrm{SiC}$ detectors, under irradiation and at elevated temperature, respond to neutrons showing consistent counting rates as function of external reverse bias voltages and radiation intensity. The counting-rate of the thermal neutroninduced peak increases with the area of the detector, and appears to be linear with respect to the reactor power. Diamond is another semi-conductor considered as one of most promising materials for radiation detection. Diamond possesses several advantages in comparison to other semiconductors such as a wider band gap (5.5 $\mathrm{eV})$, higher threshold displacement energy $(40-50 \mathrm{eV})$ and thermal conductivity $(22 \mathrm{~W} / \mathrm{cm} / \mathrm{K})$, which leads to low leakage current values and make it more radiation resistant that its competitors. A comparison is proposed between these two semiconductors for the ability and efficiency to detect fast neutrons. For this purpose the deuterium-tritium neutron generator of Technical University of Dresden with $14 \mathrm{MeV}$ neutron output of $10^{10} \mathrm{n}^{-1}$ is used. In the present work, we interpret the first measurements and results with both $4 \mathrm{H}-\mathrm{SiC}$ and chemical vapor deposition (CVD) diamond detectors irradiated with $14 \mathrm{MeV}$ neutrons at room temperature.
\end{abstract}

Index Terms - $4 \mathrm{H}-\mathrm{SiC}$, neutron detector, $\mathrm{SiC}$ neutron detector, Diamond neutron detector, fast neutron detection

The research work was supported by the CEA Cadarache

O. Obraztsova, L. Ottaviani, O. Palais are with Université Aix-Marseille, Marseille 13397, France (e-mail: olga.obraztsova@im2np.fr; laurent.ottaviani@im2np.fr; olivier.palais@im2np.fr).

A. Klix is with the Karlsruhe Institute of Technology, Institute of Neutron Physics and Reactor Technology, Karlsruhe 76344, Germany (e-mail: Axel.Klix@kit.edu).

T.Döring is with Technical university of Dresden (e-mail: Toralf.Doering@mailbox.tu-dresden.de

A. Lyoussi is with the Laboratoire Dosimétrie Capteurs Instrumentation, CEA, Cadarache 13108, France (e-mail: Abdallah.Lyoussi@cea.fr).

\section{INTRODUCTION}

$\mathrm{N}$ EUTRON detector plays a crucial role in many applications where the neutron spectrometry and flux monitoring are important such as the experiments at the material testing reactors (MTR), high energy particle physics experiments or fusion facilities for plasma diagnostics.

These last years the semiconductor-based detectors have received considerable attention thanks to their fast responses, low operating voltage, high energy resolution and radiation resistance. Most suitable semiconductors for harsh environment applications are Silicon-Carbide (SiC) and diamond thanks to their high atomic displacement energy, which is about 20-35 eV [1] for $\mathrm{SiC}$ and 40-50 eV [2] for diamond. The high displacement threshold energy makes them more radiation resistant than the conventional semiconductors such as Silicone (Si), Germanium (Ge) and Gallium Arsenide (GaAs) [3]. Moreover, the wide-bandgap energy and low intrinsic carrier concentration over considerable range of temperature make $\mathrm{SiC}$ and diamond interesting for use at high temperature applications.

The capability of the diamond-based detector to perform 14 $\mathrm{MeV}$ neutrons spectrometry using the ${ }^{12} \mathrm{C}(\mathrm{n}, \alpha){ }^{9} \mathrm{Be}$ reaction with the energy resolution of $1.5-6 \%$ has been demonstrated by several authors [4-7]. The $14 \mathrm{MeV}$ neutron radiation hardness of diamond-based detectors has also been thoroughly studied by some scientific groups. Angelone et al. [8] reported that diamond detector show the stable operation under 14 $\mathrm{MeV}$ neutrons irradiation up to the neutron fluence of $4 \times 10^{14}$ $\mathrm{n} / \mathrm{cm}^{2}$. Amosov et al. [9] reported that when the $14 \mathrm{MeV}$ neutrons fluence had reached $2 \times 10^{14} \mathrm{n} / \mathrm{cm}^{2}$, the characteristics of the diamond-based detector started to degrade. The count rate of ${ }^{12} \mathrm{C}(\mathrm{n}, \alpha){ }^{9} \mathrm{Be}$ reaction was then decreased by $7 \%$, energy resolution was decreased by a factor of 2.3 and the peak shifting to the left on $1 \mathrm{MeV}$ was observed. Concerning the SiC-based detectors the capability to measure the $14 \mathrm{MeV}$ neutron spectrum with the well resolved $(\sim 2.13 \%$, full width at half maximum $\mathrm{FWHM}=192 \mathrm{keV}){ }^{12} \mathrm{C}(\mathrm{n}, \alpha){ }^{9} \mathrm{Be}$ peak was demonstrated by F.H. Ruddy et al. [10]. The peak due to the ${ }^{28} \mathrm{Si}(\mathrm{n}, \alpha){ }^{25} \mathrm{Mg}$ reaction was also observed and the energy resolution of about $2.388 \% \quad(\mathrm{FWHM}=271 \mathrm{keV})$ was obtained. Moreover, the stable operation of the SiC-based detector was demonstrated during long term repeated irradiation tests with $14 \mathrm{MeV}$ neutrons at different temperatures up to $500^{\circ} \mathrm{C}$ [11]. However, a gradual degradation of the counting rate was observed. This fact was explained by decreasing of the applied 
bias voltage at high temperature in order to avoid thermal noise effects. The FWHM value of the ${ }^{12} \mathrm{C}\left(\mathrm{n}, \alpha_{0}\right){ }^{9} \mathrm{Be}$ peak increased by $11.8 \%$ at $500{ }^{\circ} \mathrm{C}(-20 \mathrm{~V})$ with respect to the estimated FWHM at room temperature $(-280 \mathrm{~V})$.

\section{BACKGROUND}

The fast neutron detection in $\mathrm{SiC}$ and diamond is directly provided by the interactions of the impinging neutron with the

${ }^{28} \mathrm{Si}$ and ${ }^{12} \mathrm{C}$ nucleus via the nuclear reactions which result in the production of the ionizing particles. These particles passing through the semiconductor create the electron-hole pairs which drift in a bias electric field inducing the current.

In the case of the diamond, there are five main channels of neutron-induced reactions on carbon that participate in the detector response:

- elastic scattering ${ }^{12} \mathrm{C}(\mathrm{n}, \mathrm{n}){ }^{12} \mathrm{C}$;

- inelasting scattering ${ }^{12} \mathrm{C}\left(\mathrm{n}, \mathrm{n}^{\prime}\right){ }^{12} \mathrm{C}^{*}$. This reaction takes place if the energy of the impinging neutron is higher than 4.8 $\mathrm{MeV}$;

- ${ }^{12} \mathrm{C}\left(\mathrm{n}, \mathrm{n}^{\prime}\right) 3 \alpha$ with the neutron threshold energy of $\mathrm{E}_{\mathrm{n}}=8.428 \mathrm{MeV}$;

- ${ }^{12} \mathrm{C}\left(\mathrm{n}, \alpha_{0}\right){ }^{9} \mathrm{Be}$ with the neutron threshold energy of $\mathrm{E}_{\mathrm{n}}=6.419 \mathrm{MeV}$. This reaction results in the production of the $\alpha$ particle and the ${ }^{9} \mathrm{Be}$ recoil nuclei with the energy $\mathrm{E}_{\alpha+\mathrm{Be}}=\mathrm{E}_{\mathrm{n}}-$ $5.7 \mathrm{MeV}$.

- ${ }^{12} \mathrm{C}\left(\mathrm{n}, \alpha_{1}\right){ }^{9} \mathrm{Be}$ with the neutron threshold energy of $\mathrm{E}_{\mathrm{n}}=8.09 \mathrm{MeV}$.

In the case of the $\mathrm{SiC}$, the detector response contains the contribution from the reactions with both ${ }^{28} \mathrm{Si}$ and ${ }^{12} \mathrm{C}$ nucleus. Additionally to the reactions mentioned earlier the following reactions will contribute to the detector response:

- elastic scattering ${ }^{28} \mathrm{Si}(\mathrm{n}, \mathrm{n}){ }^{28} \mathrm{Si}$;

- inelastic scattering ${ }^{28} \mathrm{Si}\left(\mathrm{n}, \mathrm{n}^{\prime}\right)^{28} \mathrm{Si}^{*}$ which takes place if the neutron energy is higher than $1.8 \mathrm{MeV}$;

- ${ }^{28} \mathrm{Si}(\mathrm{n}, \alpha)^{25} \mathrm{Mg}$ with the neutron threshold energy of $\mathrm{E}_{\mathrm{n}}=$ 2.76 MeV;

- ${ }^{28} \mathrm{Si}(\mathrm{n}, \mathrm{p})^{28} \mathrm{Al}$, with the neutron threshold energy of $\mathrm{E}_{\mathrm{n}}=$ $4 \mathrm{MeV}$.

The most important reaction for fast neutron detection is the ${ }^{12} \mathrm{C}\left(\mathrm{n}, \alpha_{0}\right)^{9} \mathrm{Be}$ reaction which occurs if the neutron energy is higher than $6.4 \mathrm{MeV}$. If the neutron flux is monoenergetic this reaction produces a well-defined peak which is useful for fast neutron spectrometry and evaluation of the energy resolution of the measurement system (detector+electronics).

\section{DEVICES}

In this work we studied two detectors. The first detector is the $4 \mathrm{H}-\mathrm{SiC}$-based detector designed by IM2NP laboratory of the Aix-Marseille University. The second detector is the diamond-based detector produced by CIVIDEC Instrumentation Company.

\section{A. 4H-SiC-based neutron detector}

The $\mathrm{SiC}$ detector is based on a $4 \mathrm{H}-\mathrm{SiC} \mathrm{p}^{+} \mathrm{n}$ diode which has been fabricated using a $4 \mathrm{H}-\mathrm{SiC} \mathrm{n}^{+}$wafer purchased from Ascatron with a substrate of $350 \mu \mathrm{m}$ thickness, on which a 20$\mu \mathrm{m}$ thick n-type epitaxial layer with a low nitrogen doping concentration $\sim 2 \times 10^{14} \mathrm{~cm}^{-3}$ was grown. To create the pnjunction a $1-\mu \mathrm{m}$ thick $\mathrm{p}+$ epitaxial layer with a high aluminum doping concentration $\sim 10^{19} \mathrm{~cm}^{-3}$ was deposited on the n-type layer. Next the ohmic contact $(\mathrm{Ni} / \mathrm{Ti} / \mathrm{Al} / \mathrm{Ni})$ with $200 \mathrm{~nm}$ thickness has been deposited by ultrahigh vacuum electron beam evaporation. In order to reduce the contact resistance a 1 $\mu \mathrm{m} \mathrm{Al}$ metallic contact has been deposited under ultrahigh vacuum electron beam evaporation on the top of the ohmic contact. Then a $\mathrm{Ti} / \mathrm{Ni} / \mathrm{Au} 555-\mathrm{nm}$ thick overmetallization was deposited. In the present work the area of the investigated diode was $0.33 \mathrm{~cm}^{2}$. The schematical representation of this diode is illustrated in Fig.1.

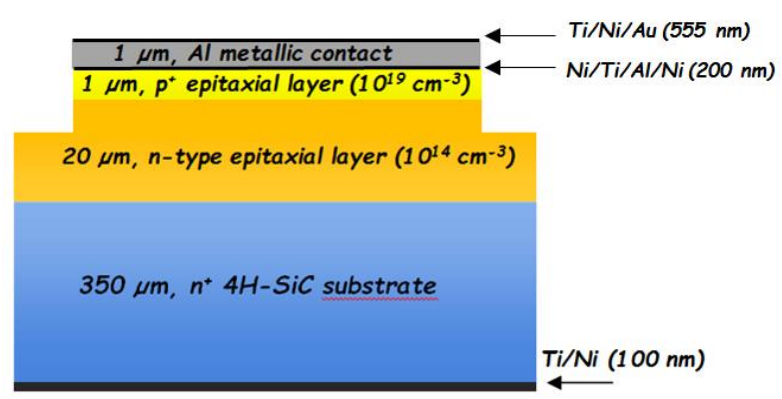

Fig. 1. Schematic representation of the investigated $4 \mathrm{H}-\mathrm{SiC}$-based diode.

\section{B. Diamond-based neutron detector}

The diamond-based detector has been purchased from CIVIDEC Instrumentation Company. This detector is based on a single crystal CVD (sCVD) diamond of the $500 \mu \mathrm{m}$ thickness. It has the capacitor-type configuration also named the solid-state ionization chamber [12].

\section{MEASUREMENT SETUP AND CONDITIONS}

The measurements were carried out at the deuterium-tritium (DT) neutron generator at Technical University of Dresden. Two different neutron detectors, one SiC-based and one SCVD diamond-based were used in this study. The experimental conditions were the same for both detectors. The detectors were positioned $13 \mathrm{~cm}$ away from the tritium target at an angle of $90^{\circ}$ with respect to the deuterium beam. The neutron flux at this point was $9.4 \times 10^{6} \mathrm{n} /\left(\mathrm{cm}^{2} \mathrm{~s}\right)$ with the neutron energy of 14.12 MeV.

The detectors were connected to the CAEN A1422 charge sensitive preamplifier (CSP) and operated simultaneously. The $\mathrm{SiC}$ detector operated at $-120 \mathrm{~V}$ bias voltage while the sCVD diamond at $120 \mathrm{~V}$. The bias voltage was provided by CAEN DT 5519M HV bias supply via the charge sensitive preamplifier. The signal output of the CSP was connected to the ORTEC amplifier which amplifies and reshapes the pulses coming from the CPS before digitization in an analog to digital converter (ADC). 


\section{ENERGY CALIBRATION}

For the energy calibration of the recorded spectrum the peak due to the ${ }^{12} \mathrm{C}\left(\mathrm{n}, \alpha_{0}\right){ }^{9} \mathrm{Be}$ reaction was used. The channel numbers of the multichannel analyzer are directly linked to the energy deposited into the active volume of the detector by charged reaction products. The sum of the energies of the $\alpha$ particle and the ${ }^{9} \mathrm{Be}$ recoil nuclei depends only on the energy of the incoming neutron $\mathrm{E}_{\alpha+\mathrm{Be}}=\mathrm{E}_{\mathrm{n}}-5.7 \mathrm{MeV}$, where $\mathrm{E}_{\mathrm{n}}$ is the energy of the incoming neutron, $-5.7 \mathrm{MeV}$ corresponds to the Q-value of the ${ }^{12} \mathrm{C}\left(\mathrm{n}, \alpha_{0}\right){ }^{9} \mathrm{Be}$ reaction.

In order to calibrate the spectrum the measurements at different angles with respect to the deuterium beam were implemented. The distance from the tritium target was about $13 \mathrm{~cm}$. The energy of the neutrons vary from $13.7 \mathrm{MeV}$ to 14.89 $\mathrm{MeV}$ depending on the relative detector position to the deuterium beam. At $90^{\circ}$ the neutron energy is $14.12 \mathrm{MeV}$ and the energy distribution is the narrowest. The maximum mean neutron energy of $14.89 \mathrm{MeV}$ is reached at $0^{\circ}$. However at $0^{\circ}$ the significant broadening of the neutron energy distribution exist and affect the ${ }^{12} \mathrm{C}\left(\mathrm{n}, \alpha_{0}\right){ }^{9} \mathrm{Be}$ peak resolution. The comparative study of the responses of SiC-based and diamond-based detectors to $14 \mathrm{MeV}$ neutrons were then realized at an angle of $90^{\circ}$ with respect to the deuterium beam.

The measured ${ }^{12} \mathrm{C}\left(\mathrm{n}, \alpha_{0}\right){ }^{9} \mathrm{Be}$ peak positions in the channels and the relevant energies are presented in the Fig.2. for $\mathrm{SiC}$ and in the Fig.3. for diamond.

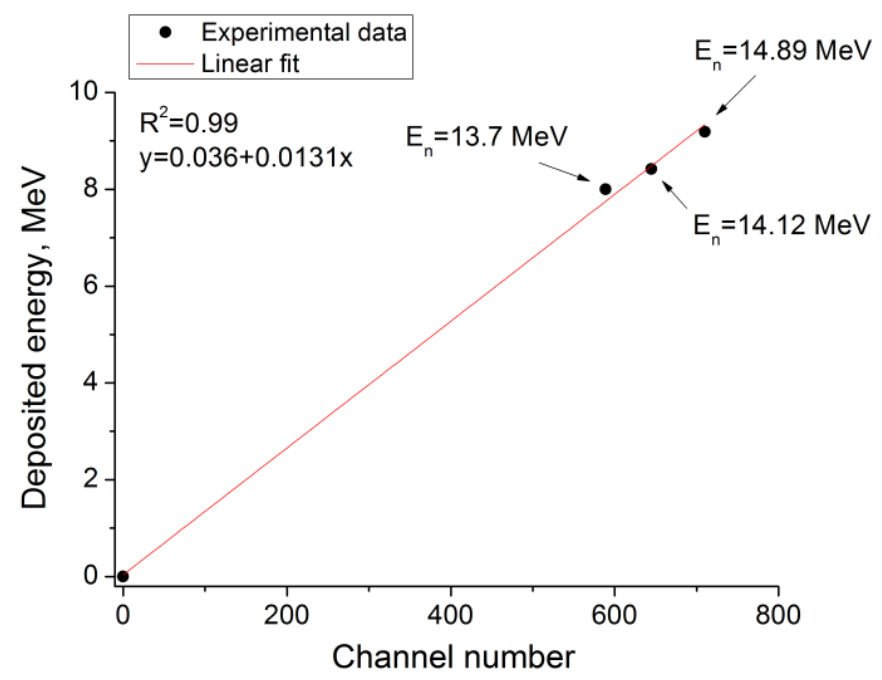

Fig. 2. Energy calibration for the ${ }^{12} \mathrm{C}\left(\mathrm{n}, \mathrm{\alpha}_{0}\right){ }^{9} \mathrm{Be}$ reaction peak for SiC-based detector.

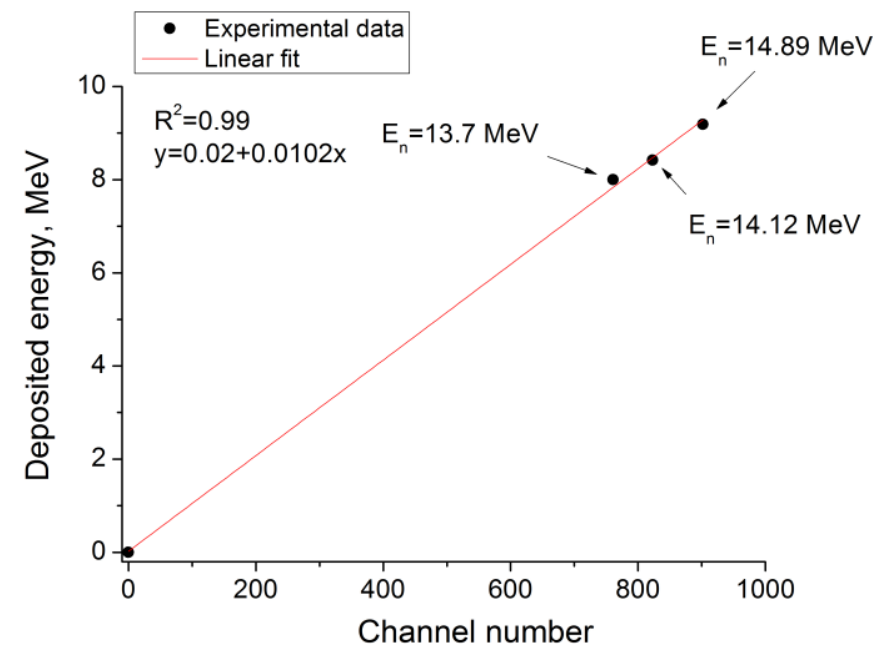

Fig. 3. Energy calibration for the ${ }^{12} \mathrm{C}\left(\mathrm{n}, \mathrm{\alpha}_{0}\right){ }^{9} \mathrm{Be}$ reaction peak for diamondbased detector.

\section{RESULTS AND DISCUSSIONS}

The pulse-height spectrum (PHS) of the SiC-based and sCVD diamond-based detectors for $14.12 \mathrm{MeV}$ neutrons are shown in Fig.4. At the low energies below $4 \mathrm{MeV}$ the elastic and inelastic scattering of the neutrons on ${ }^{12} \mathrm{C}$ and ${ }^{28} \mathrm{Si}$ nucleus dominate the response of the $\mathrm{SiC}$ detector. Of course, in the case of the diamond only the contribution from the neutron scattering on ${ }^{12} \mathrm{C}$ nucleus exists. At the higher energies the well-defined peak due to the ${ }^{12} \mathrm{C}\left(\mathrm{n}, \alpha_{0}\right){ }^{9} \mathrm{Be}$ reaction can be clearly identified for both detectors. For the neutron energy of 14.12 $\mathrm{MeV}$ the energy deposited by the $\alpha$ particle and the ${ }^{9} \mathrm{Be}$ recoil nuclei is about $8.4 \mathrm{MeV}$. The contribution from the ${ }^{12} \mathrm{C}\left(\mathrm{n}, \alpha_{1}\right){ }^{9} \mathrm{Be}$ which results in the production of the charged products with the total energy of $6.72 \mathrm{MeV}$ is obscured by the ${ }^{12} \mathrm{C}(\mathrm{n}, \mathrm{n}$ ') $3 \alpha$ continuum. In the response of the $\mathrm{SiC}$ detector some peaks is observed in the energy range from 7 to $10 \mathrm{MeV}$ which are absent for the diamond and can be explained by the contribution from the multiple branches of the ${ }^{28} \mathrm{Si}(\mathrm{n}, \alpha)^{25} \mathrm{Mg}$ reaction observed by F.H. Ruddy et al.[10] for a SiC detector.

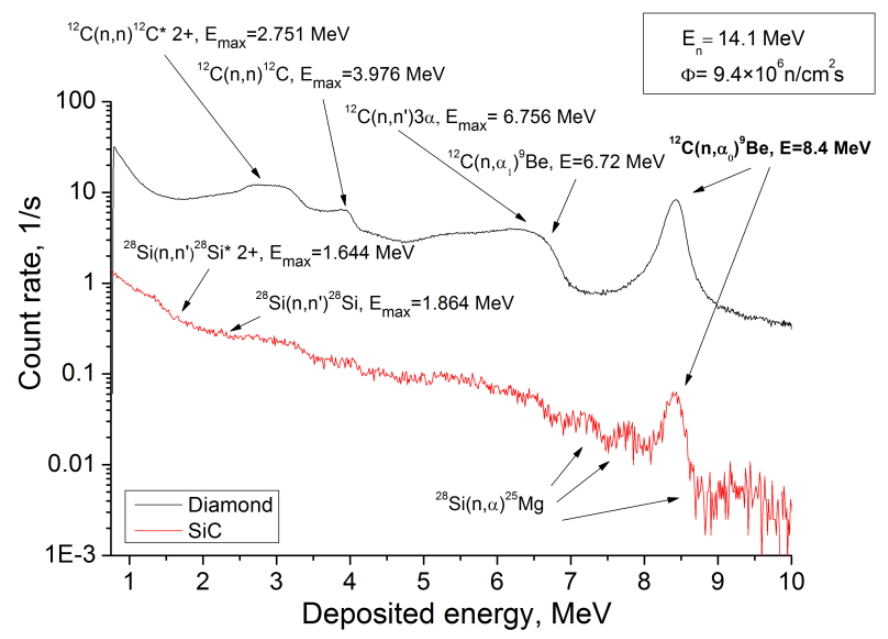

Fig. 4. Comparison of the responses of the SiC-based and SCVD diamondbased detectors to $14.12 \mathrm{MeV}$ neutrons. 
The main difference between the two responses is the higher count rate with the diamond-based detector than with the $\mathrm{SiC}$ based one. At the neutron flux of $9.4 \times 10^{6} \mathrm{n} /\left(\mathrm{cm}^{2} \mathrm{~s}\right)$ the total count rate of the diamond detector is equal to $4.8 \times 10^{3} \mathrm{c} / \mathrm{s}$ and $2.46 \times 10^{2} \mathrm{c} / \mathrm{s}$ for the $\mathrm{SiC}$ detector. The lower count rate of the $\mathrm{SiC}$ can be explained by a smaller thickness of its active detection volume which is limited by the width of the space charge region (SCR). The SCR width depends on the value of the applied reverse-biased voltage. At $-120 \mathrm{~V}$ the SCR is about $21 \mu \mathrm{m}$ and reaches its maximum value. For the diamond-based detector the thickness of the detection volume is $500 \mu \mathrm{m}$, which corresponds to the thickness of the single crystal CVD diamond.

\section{CONCLUSION}

This work has been conducted to compare the responses of the SiC-based and diamond-based detectors of the most commonly used configurations to $14 \mathrm{MeV}$ neutrons irradiation. The linear relation between channel number and energy was obtained for ${ }^{12} \mathrm{C}\left(\mathrm{n}, \alpha_{0}\right){ }^{9} \mathrm{Be}$ reaction peak for both detectors. Moreover, both detectors showed well-characterized pulse-height spectrum with the well-resolved peak due to the ${ }^{12} \mathrm{C}\left(\mathrm{n}, \alpha_{0}\right){ }^{9} \mathrm{Be}$ reaction. However, the count rate of the diamond-based detector has been higher than the count rate of the SiC-based detector. This fact is due to the smaller thickness of the active detection volume of the SiC-based detector which is limited to $21 \mu \mathrm{m}$.

\section{REFERENCES}

G. Lucas, L. Pizzagalli, "Comparison of threshold displacement energies in $\beta$-SiC determined by classical potentials and ab initio calculations", Nucl. Instr. and Meth. in Phys. Res., B 229, pp. 359. $366,2005$.

[2] J. C. Bourgoin, B. Massarani, "Threshold energy for atomic displacement in diamond", Phys. Rev. B 14, pp. 3690-3694, 1976.

[3] F. Nava, G. Bertuccio, A. Cavallini, and E. Vittone, "Silicon carbide and its use as a radiation detector material", Meas. Sci. Technol., vol. 19 , no. 10 , p. 102001 , Oct. 2008.

[4] A. V. Krasilnikov, J. Kaneko, M. Isobe, F. Maekawa, and T. Nishitani, "Fusion neutronic source deuterium-tritium neutron spectrum measurements using natural diamond detectors", Rev. Sci. Instrum. 68, pp. 1720-1724, 1997

T.Shimaoka, J.H. Kaneko, K. Ochiai et al.,"A diamond $14 \mathrm{MeV}$ neutron energy spectrometer with high energy resolution", Rev. Sci. Instrum. 87, p. 023503, 2016

C. Cazzaniga, M. Nocente, M. Rebai, et al., "A diamond based neutron spectrometer for diagnostics of deuterium-tritium fusion plasmas", Rev. Sci. Instrum. 85, p.11E101, 2014
M. Angelone, M. Pillon, A. Balducci, «Radiation hardness of a polycrystalline chemical-vapor-deposited diamond detector irradiated with $14 \mathrm{MeV}$ neutrons», Rev. Sci. Instrum 77, p. 023505, 2006

V.N. Amosov, S.A. Meshchaninov, N.B. Rodionov, "Тестирование алмазного нейтронного детектора на каскадном сильноточном ускорителе КГ-2,5", Prikladnaya Fizika, No. 3, pp. 80-84, 2015 [In Russian]

[10] F.H. Ruddy, A.R. Dulloo, J.G. Seidel et al., "The fast neutron response of $4 \mathrm{H}$ Silicon Carbide semiconductor radiation detectors ", IEEE Trans. Nucl. Sci., vol.53, no. 3, pp. 1666-1670, 2006

[11] D. Szalkai, R. Ferone, F. Issa, "Fast Neutron Detection With 4H$\mathrm{SiC}$ Based Diode Detector up to $500{ }^{\circ} \mathrm{C}$ Ambient Temperature", IEEE Trans. Nucl. Sci.SCIENCE, vol. 63, no. 3, 2016

[12] P. Kavrigin, P. Finocchiaro, E. Griesmayer et al., "Pulse-shape analysis for gamma background rejection in thermal neutron radiation using CVD diamond detectors", Nuclear Instruments and Methods in Physics Research A 795, pp. 88-91, 2015 